\title{
Health disparities caused by geogenic manganese contamination of groundwater in California
}

MirANDA AIKEN*1, MAITHILI RAMACHANDRAN2, KURT SCHWABE3, BENJAMIN MAKI1, SAMANTHA C. YING4

1Department of Environmental Toxicology, University of California Riverside, Riverside, CA 92521, USA

${ }_{2}$ Department of Economics, University of California Riverside, Riverside, CA 92521, USA

3School of Public Policy, University of California Riverside, Riverside, CA 92521, USA

4Department of Environmental Science, University of

California Riverside, Riverside, CA 92521, USA

*correspondence: maike001@ucr.edu

High levels of naturally occurring manganese $(\mathrm{Mn})$ are found in groundwater worldwide. Despite prior research suggesting consumption of drinking water with high $\mathrm{Mn}$ concentrations leads to neurotoxic effects in children, $\mathrm{Mn}$ is not regulated as a primary drinking water contaminant in California or the US. Since the fate of Mn in drinking water is greatly associated with the local biogeochemistry of the soil environment, we have investigated a potential source of Mn in drinking water through groundwater recharge efforts and how disproportionate exposure to high Mn concentrations might impact human health in California.

Increasingly, California water management agencies are implementing managed aquifer recharge (MAR) technologies to increase groundwater storage for future use; however, recent findings have indicated that geochemical conditions during recharge have the potential to mobilize high concentrations of geogenic Mn. In this work, we provide preliminary insights into the extent of Mn mobilization from flood-MAR basin implementation accompanied by a discussion of potential $\mathrm{Mn}$ release mechanisms. To explore the potential health impacts of high Mn exposure through drinking water in California, we combine existing groundwater geochemical and health outcome data (i.e. infant birth weight) to determine if regions with high probability of $\mathrm{Mn}$ exposure through groundwater is correlated with adverse health effects. 